\title{
Effectiveness of different carbamide peroxide concentrations used for tooth bleaching: an in vitro study
}

Sônia Saeger MEIRELES', Silvia Terra FONTES², Luiz Antônio Afonso COIMBRA³, Álvaro DELLA BONA4, Flávio Fernando DEMARCO ${ }^{5}$

\footnotetext{
1- DDS, PhD, Adjunct Professor, Department of Operative Dentistry, Federal University of Paraíba, João Pessoa, PB, Brazil.

2- DDS, MS, PhD student in Operative Dentistry, Federal University of Pelotas, Pelotas, RS, Brazil.

3- Undergraduate student in Dentistry, Federal University of Pelotas, Pelotas, RS, Brazil.

4- DDS, MMedSci, PhD, Professor, School of Dentistry, University of Passo Fundo, Passo Fundo, RS, Brazil.

5- DDS, PhD, Associate Professor, Department of Operative Dentistry, Federal University of Pelotas, Pelotas, RS, Brazil.
}

Corresponding address: Sônia Saeger Meireles - UFPB, Campus I, CCS, Depto de Odontologia Restauradora - Castelo Branco - $58051-900$ - João Pessoa - PB - Brazil - Phone: + 8332167250 - e-mail: soniasaeger@hotmail.com

Received: June 2, 2010 - Modification: June 9, 2011 - Accepted: July 8, 2011

\section{ABSTRACT}

$\mathrm{O}$ bjectives: This in vitro study evaluated the effectiveness of three carbamide peroxide concentrations used for tooth bleaching treatments. Material and Methods: Sixty bovine dental slabs $(6 \times 6 \times 3 \mathrm{~mm})$ were obtained, sequentially polished, submitted to artificial staining (baseline) and randomized into four groups $(n=15)$, according to the bleaching agent concentration: distilled water (control), $10 \%$ (CP10), $16 \%$ (CP16) or $37 \%$ (CP37) carbamide peroxide. CP10 and CP16 were covered with $0.2 \mathrm{~mL}$ of the respective bleaching gels, which were applied on enamel surface for $4 \mathrm{~h} /$ day during two weeks. Samples of CP37 were covered with $0.2 \mathrm{~mL}$ of the bleaching gel for $20 \mathrm{~min}$. The gel was light activated by two 40-s applications spaced by 10-min intervals. The gel was renewed and applied 3 times per clinical session. This cycle was repeated at 3 sessions with 5 days of interval between them. Tooth shade evaluations were done with a digital spectrophotometer at T0 (baseline), T1 (after 1-week of treatment) and T2 (1-week post-bleaching). Tooth shade means were statistically analyzed by Kruskal-Wallis and Friedman's tests and color parameters were analyzed by two-way ANOVA and Tukey's test $(p<0.05)$. Results: At T1 and T2 evaluations, tooth shade was significantly lighter than at baseline for all treatment groups, considering the color parameters $\Delta L^{*}, \Delta a^{*}, \Delta b^{*}, \Delta E^{*}(p<0.001)$ or tooth shade means $(p<0.001)$. CP37 group showed lower shade mean change than CP10 and CP16 at T1 $(p<0.01)$, but this difference was not statistically significant at T2 ( $p>0.05)$. Conclusions: One week after the end of the treatment, all carbamide peroxide concentrations tested produced similar tooth color improvement.

Key words: Tooth bleaching. Peroxides. In vitro.

\section{INTRODUCTION}

Tooth color is an important issue for esthetic dentistry professionals and for patients that wish to enhance the appearance of their smiles. Nowadays, at-home vital tooth bleaching with custom trays is well accepted as a safe, conservative, low cost and effective esthetic procedure for treatment of discolored teeth ${ }^{10}$. Considering the active products available for vital tooth bleaching, carbamide and hydrogen peroxide are the most commonly used agents for different bleaching modalities ${ }^{4,9,10}$, which vary according to peroxide concentration, mode of application and time of exposure ${ }^{6,16}$.

The whitening products available for vital tooth bleaching can be applied on tooth surface at the office by a dentist or at home by the patient, under the dentist's supervision ${ }^{4}$. The only concentration that so far received the seal of acceptance by American Dental Association (ADA) was the 10 $1 \%$ carbamide peroxide, which assures its safety and efficacy for at-home tooth bleaching with custom 
trays ${ }^{2}$. Previous studies have reported the efficacy and safety of this bleaching gel concentration ${ }^{18,20}$. However, randomized clinical trials showed that the increase of the carbamide peroxide concentration for home-use did not increase the efficacy and longevity of the tooth whitening effect ${ }^{20,21}$.

Manufacturers have introduced many different bleaching agents' concentrations and methods with the premise of "improving" the whitening effect ${ }^{10}$. As a consequence, there was a significant increase of the variety of in-office tooth bleaching products available in the market, which usually uses high hydrogen (15 to $40 \%$ ) or carbamide (30 to $37 \%$ ) peroxide concentrations combined or not with a supplementary light source (i.e. laser, LED, halogen lamp or plasma arc $)^{7,16}$. Despite the method of activation of these agents, the data available in the literature are conflicting. While some studies have reported that the use of light sources can enhance the whitening effect ${ }^{13,22}$, others have shown that the use of light-activation with in-office tooth bleaching did not affect the outcome of $35 \%$ hydrogen peroxide treatment ${ }^{1,14,15}$.

Considering the peroxide concentration and its time of application as the main factors that can affect the effectiveness of tooth whitening, the aim of the present study was to evaluate the effectiveness of three carbamide peroxide concentrations used in tooth bleaching treatments. The null hypothesis for this study was that the highconcentration carbamide peroxide gel evaluated is not more effective than the low-concentration carbamide peroxide bleaching agents.

\section{MATERIAL AND METHODS}

\section{Specimen preparation}

Sixty recently extracted bovine incisors without cracks and surface defects (40x magnification) were used in this study. The roots were cut with a water-cooled low-speed diamond saw (Isomet 1000, Buehler, Lake Bluff, IL, USA) and, the pulp tissue was removed. Then, teeth were stored in $0.5 \%$ chloramine-T solution for one week.

After disinfection, each crown was sectioned in both buccolingual and mesiodistal directions to obtain one enamel-dentin slab $(6 \times 6 \times 3 \mathrm{~mm})$, which were measured with a digital caliper (DC 500, Mitutoyo, Suzano, SP, Brazil). Each slab was individually embedded in self-curing acrylic resin in a ring model and then, enamel surfaces were flattened with 600- and 1200-grit silicon-carbide paper under water cooling to create a standardized buccal enamel surface. Samples were washed and stored in distilled water at $37^{\circ} \mathrm{C}$ for 1 week until starting the experimental procedures.

\section{Staining procedure}

In an attempt to standardize the tooth shade, an artificial staining of the specimens was carried out following the method proposed by Sulieman, et al. ${ }^{24}$ (2003). Enamel surfaces were etched with $35 \%$ phosphoric acid gel for $60 \mathrm{~s}$ and rinsed with distilled water for $30 \mathrm{~s}$. Specimens were immersed daily over a 1-week period in a standardized coffee solution at room temperature $\left(25 \pm 2^{\circ} \mathrm{C}\right)$ in screw capped plastic universal containers. The daily renewed coffee solution was produced by boiling $12 \mathrm{~g}$ of coffee (Melitta, Avaré, SP, Brazil) in $200 \mathrm{~mL}$ of distilled water for 5 min followed by filtering in a coffee maker (Melitta). After the immersion period, the specimens were washed and stored in distilled water at room temperature.

\section{Tooth shade measurement}

Tooth shades of the stained specimens were assessed with a digital spectrophotometer (Vita Easyshade, Vita Zahnfabrik, Bad Sackingen, Germany) after 1, 3 and 7 days of immersion in coffee solution (baseline). Three measurements were done with the active point of the spectrophotometer in the center of each sample. The instrument automatically averaged the three readings for each sample, which were use for overall data analysis. The digital spectrophotometer measures the tooth shade based on two methods: by grouping shades according to the 16 shade tabs in the guide (Vitapan Classical, Vita Zahnfabrik), which were numbered from 1 (highest value - B1) to 16 (lowest value - C4) (Figure 1$)^{19}$ and, the CIEL*a*b* color system, which was defined by the International Commission on Illumination. In the CIELAB color system, the $L^{*}$ axis represents the value (lightness or darkness), the a* axis is a measure of redness (positive $a^{*}$ ) or greenness (negative $a^{*}$ ), and the $b^{*}$ axis is a measure of yellowness (positive $b^{*}$ ) or blueness (negative $b^{*}$ ). The difference between the color coordinates was calculated as: $\Delta \mathrm{E}^{*}=\left[\left(\Delta \mathrm{L}^{*}\right)^{2}+(\Delta \mathrm{a} *)^{2}+\left(\Delta \mathrm{b}^{*}\right)^{2}\right]^{1 / 28}$.

The same protocol used to determine the tooth shade at baseline (TO) was used in all other periods evaluated: after 1 week of treatment (T1) and 1 week post-bleaching (T2). All teeth shades measurements were performed objectively by an experienced examiner, which was blinded to the agent concentration.

\begin{tabular}{|l|c|c|c|c|c|c|c|c|c|c|c|c|c|c|c|c|}
\hline Vitapan shade guide & B1 & A1 & B2 & D2 & A2 & C1 & C2 & D4 & A3 & D3 & B3 & A3,5 & B4 & C3 & A4 & C4 \\
\hline Scores & 1 & 2 & 3 & 4 & 5 & 6 & 7 & 8 & 9 & 10 & 11 & 12 & 13 & 14 & 15 & 16 \\
\hline
\end{tabular}

Figure 1- Color scores by sequence of colors in the shade guide (from lighter to darker colors) 


\section{Bleaching procedure}

The same examiner responsible for the staining procedure carried out all bleaching treatments. The coffee-stained samples were randomly allocated into four groups $(n=15)$, according to the bleaching agent concentration: distilled water (control group), 10\% (CP10), 16\% (CP16) or $37 \%$ (CP37) carbamide peroxide. The manufacturer and chemical composition of each bleaching agent used in this study are listed in Figure 2.

The control group was stored in distilled water at $37^{\circ} \mathrm{C}$, which was daily renewed during 2 weeks. Samples of CP10 and CP16 groups were covered with $0.2 \mathrm{~mL}$ of the respective bleaching gels, which were applied on enamel surface for $4 \mathrm{~h}$ / day during 2 weeks. Samples of CP37 group were covered with $0.2 \mathrm{~mL}$ of the bleaching gel for $20 \mathrm{~min}$. The gel was light activated by two 40-s applications (LED Radii, SDI, Bayswater, Victoria, Australia) spaced by 10min intervals. The gel was renewed and applied 3 times per clinical session. This cycle was repeated at 3 sessions with 5 days of interval between them. After bleaching treatments, the gels were carefully removed with sterile gauze and tap water and then the samples were stored in distilled water at $37^{\circ} \mathrm{C}$ until the next application.

\section{Statistical analysis}

Tooth shade means were analyzed statistically by Kruskal-Wallis and Friedman's tests and color parameters were analyzed by two-way analysis of variance (ANOVA) and Tukey's test. The factors investigated were treatment group and evaluation period. The level of confidence was established at $\alpha=0.05$.

\section{RESULTS}

Tooth shade means and tooth color parameters $\left(\Delta \mathrm{L}^{*}, \Delta \mathrm{a}^{*}, \Delta \mathrm{b}^{*}, \Delta \mathrm{E}^{*}\right)$ for the treatment groups at the different evaluation periods are presented in Tables 1 and 2, respectively. At T1 and T2 evaluations, CP10, CP16 and CP37 groups showed a statistically significant decrease in tooth shade means when compared with baseline and control group $(p<0.001)$. At $T 1$, the group treated with CP37 presented lower tooth shade means than the other bleaching treatments tested in the same period $(p<0.01)$. However, the tooth shade means resulting from the 1 -week post-bleaching procedures (T2) were not statistically different between CP10, CP16 and CP37 groups ( $p>0.05$ ).

Considering tooth color parameters at T1 and T2, all treatment groups showed an increasing of the lightness $\left(\Delta L^{*}\right)$, a decreasing of the redness $\left(\Delta \mathrm{a}^{*}\right)$ and yellowness $\left(\Delta \mathrm{b}^{*}\right)$ compared with baseline $(p<0.001)$. However, the increasing of the lightness $\left(\Delta L^{*}\right)$ in the group treated with CP37 was lower than CP10 and CP16 at both evaluations periods $(p<0.001)$. Although a* values decreased for all treatment groups, at T2, there was no statistically difference among CP10, CP16, CP37 and control $(p>0.06)$. The decrease of $b *$ values in CP37 was significantly lower than in the other treatment

\begin{tabular}{|c|c|c|}
\hline Product & Manufacturer & Chemical composition \\
\hline Whiteness Perfect 10\% & FGM, Joinville,SC, Brazil & $\begin{array}{c}10 \% \text { carbamide peroxide, carbopol, potassium } \\
\text { nitrate, sodium fluoride, glycol and deionized water. }\end{array}$ \\
\hline Whiteness Perfect 16\% & FGM, Joinville, SC, Brazil & $\begin{array}{c}16 \% \text { carbamide peroxide, carbopol, potassium } \\
\text { nitrate, sodium fluoride, glycol and deionized water. }\end{array}$ \\
\hline Whiteness Super 37\% & FGM, Joinville, SC, Brazil & $\begin{array}{r}37 \% \text { carbamide peroxide, carbopol, potassium ions, } \\
\text { glycol and deionized water. }\end{array}$ \\
\hline
\end{tabular}

Figure 2- Description of the bleaching agents used in this study

Table 1- Tooth shade means and standard deviations $( \pm S D)$ for the different treatment groups according to the evaluation periods

\section{Treatment groups}

\section{Evaluation periods}

T1

(1-week of treatment)

(baseline)

$\begin{array}{ll}\text { Control } & \mathrm{A} 12.9( \pm 1.7)^{\mathrm{a}} \\ \text { CP10 } & \mathrm{A} 12.7( \pm 2.6)^{\mathrm{a}} \\ \mathrm{CP} 16 & \mathrm{~A} 12.7( \pm 1.8)^{\mathrm{a}} \\ \mathrm{CP} 37 & \mathrm{~A} 11.8( \pm 2.5)^{\mathrm{a}}\end{array}$

$\begin{array}{ll}{ }^{\mathrm{A}} 12.4( \pm 1.3)^{\mathrm{a}} & { }^{\mathrm{A}} 12.5( \pm 0.7)^{\mathrm{a}} \\ { }^{\mathrm{B}} 4.4( \pm 2.1)^{\mathrm{b}} & { }^{\mathrm{C}} 2.9( \pm 0.7)^{\mathrm{b}} \\ { }_{\mathrm{B}}^{\mathrm{B}} 4.1( \pm 2.2)^{\mathrm{b}} & { }^{\mathrm{C}} 2.3( \pm 1.3)^{\mathrm{b}} \\ { }_{\mathrm{B}} 7.0( \pm 3.2)^{\mathrm{C}} & { }^{\mathrm{C}} 2.4( \pm 0.6)^{\mathrm{b}}\end{array}$

Different capital letters indicate statistically significant differences only among the evaluation periods $(p<0.001)$. Different lowercase letters indicate statistically significant differences only among the treatment groups $(p<0.001)$. 
Table 2- Tooth color parameter means and standard deviations $( \pm S D)$ for the different treatment groups according to the evaluation periods

\begin{tabular}{|c|c|c|c|c|}
\hline \multirow[t]{2}{*}{ Color parameters } & \multirow[t]{2}{*}{ Treatment groups } & \multicolumn{3}{|c|}{ Evaluation periods } \\
\hline & & $\begin{array}{c}\text { T0 } \\
\text { (baseline) }\end{array}$ & $\begin{array}{c}\mathrm{T} 1 \\
\text { (1-week of treatment) }\end{array}$ & $\begin{array}{c}\mathrm{T} 2 \\
\text { (1-week after treatment) }\end{array}$ \\
\hline \multirow[t]{4}{*}{$\Delta \mathrm{L}^{*}$} & Control & A $77.2( \pm 4.2)^{\mathrm{a}}$ & в $1.9( \pm 2.4)^{a}$ & 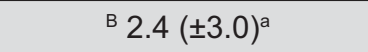 \\
\hline & CP10 & A $76.4( \pm 4.5)^{\mathrm{a}}$ & В $10.1( \pm 4.2)^{b}$ & $\mathrm{c} 12.1( \pm 5.6)^{\mathrm{b}}$ \\
\hline & CP16 & A $75.6( \pm 4.2)^{\mathrm{a}}$ & В $12.6( \pm 3.7)^{b}$ & c $15.6( \pm 6.7)^{b}$ \\
\hline & CP37 & A $79.3( \pm 2.8)^{\mathrm{a}}$ & 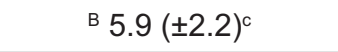 & ${ }^{\text {B }} 6.2( \pm 2.3)^{\mathrm{C}}$ \\
\hline \multirow[t]{4}{*}{$\Delta \mathrm{a}^{*}$} & Control & ${ }^{\text {A }} 2.5( \pm 2.3)^{\mathrm{a}}$ & ${ }^{\mathrm{B}}-1.0( \pm 0.8)^{\mathrm{a}}$ & ${ }^{c}-1.7( \pm 1.6)^{a}$ \\
\hline & CP10 & А $2.4( \pm 2.9)^{\mathrm{a}}$ & ${ }^{\text {B }}-2.6( \pm 1.9)^{b}$ & ${ }^{\mathrm{B}}-2.7( \pm 2.1)^{\mathrm{a}}$ \\
\hline & CP16 & A $1.7( \pm 2.1)^{\mathrm{a}}$ & ${ }^{B}-2.5( \pm 1.5)^{b}$ & ${ }^{B}-2.3( \pm 1.4)^{a}$ \\
\hline & CP37 & ${ }^{\mathrm{A}} 2.5( \pm 2.4)^{\mathrm{a}}$ & ${ }^{\text {В }}-2.8( \pm 2.0)^{b}$ & ${ }^{c}-3.4( \pm 1.9)^{a}$ \\
\hline \multirow[t]{4}{*}{$\Delta \mathrm{b}^{*}$} & Control & ${ }^{\text {A }} 36.4( \pm 5.0)^{\mathrm{a}}$ & ${ }^{\text {B }}-1.4( \pm 1.9)^{a}$ & ${ }^{c}-2.7( \pm 3.4)^{a}$ \\
\hline & $\mathrm{CP} 10$ & ${ }^{\text {A }} 36.1( \pm 4.2)^{\mathrm{a}}$ & B $-7.6( \pm 3.1)^{b}$ & В $-7.6( \pm 2.2)^{\mathrm{b}}$ \\
\hline & CP16 & ${ }^{\text {A }} 32.0( \pm 4.0)^{\mathrm{a}}$ & B $-5.8( \pm 3.4)^{b}$ & B $-5.0( \pm 3.3)^{\mathrm{ab}}$ \\
\hline & CP37 & A $36.0( \pm 5.2)^{\mathrm{a}}$ & В $-7.1( \pm 4.1)^{\mathrm{b}}$ & c $-11.0( \pm 4.0)^{c}$ \\
\hline \multirow[t]{4}{*}{$\Delta \mathrm{E}$} & Control & --- & А $3.6( \pm 1.9)^{a}$ & в $5.5( \pm 2.9)^{a}$ \\
\hline & CP10 & --- & A $13.5( \pm 3.9)^{b}$ & A $15.1( \pm 5.0)^{b}$ \\
\hline & CP16 & --- & A $14.4( \pm 3.9)^{b}$ & В $16.8( \pm 4.1)^{b}$ \\
\hline & CP37 & --- & A $10.1( \pm 3.9)^{\mathrm{C}}$ & в $13.6( \pm 3.5)^{b}$ \\
\hline
\end{tabular}

At baseline, $L^{*}, a^{*}, b^{*}$ means were shown in absolute values. Different capital letters indicate statistical significant differences only between evaluation periods $(p<0.05)$. Different lowercase letters indicate statistical significant differences only between treatment groups $(p<0.05)$.

groups $(p<0.001)$. Despite $\Delta E^{*}$ values, there was no difference among the treatment groups at the end of the treatment $(p>0.1)$.

\section{DISCUSSION}

Previous studies have suggested that the two main factors that determine the tooth whitening efficacy are the peroxide concentration and its time of application ${ }^{11,16}$. There is a belief that the increase of the bleaching agent concentration can produce a higher and faster whitening effect compared with whitening products with low-concentration bleaching agents. However, this study showed that after the first week of treatment, 10 and $16 \%$ carbamide peroxide concentrations were significantly more effective than the $37 \%$ concentration. From this study, it appears that the factor contact time of bleaching agent was more important than the concentration of gels. Although this result might seem surprising, similar effects in tooth shade improvement were achieved with longer treatment times, independently of the peroxide concentration used $^{16,17}$. A review that compared 9 clinical trials and the effectiveness of 25 tooth whitening products showed that tooth whitening is more effective when the bleaching agent is placed in trays ${ }^{16}$.
As the present in vitro study followed the manufacturers' recommendations in order to evaluate the effectiveness of carbamide peroxidebased gels available for in-office bleaching (37\%) or home-use ( 10 and $16 \%$ ), the mode and duration of applications were different among the groups. Certainly, these different characteristics of application for each bleaching agent might have influenced the outcome of tooth whitening 9,12,23. A clinical trial that evaluated the effectiveness of 8 in-office tooth whitening systems verified that the contact time between bleaching gel and tooth surface is an important factor that can improve the outcome of the bleaching treatment ${ }^{17}$.

The necessity of light-activation of peroxidebased gels has already been questioned by some authors $7,13,15,22$. Even though the use of light in bleaching procedures has been considered unnecessary ${ }^{1,14}$ because of the presence of other agents (i.e., carbopol) that assure the catalyze of peroxides, light-activation of $37 \%$ carbamide peroxide was performed in our study to accelerate the whitening process, following the manufacturer's instructions.

Despite the subjectivity of visual tooth color assessment, it has been well documented that the tooth color changes can be successfully 
assessed using both shade guides and digital spectrophotometry ${ }^{3,19}$. Nevertheless, when employing an objective method for measuring the tooth color changes, it is also possible to evaluate color parameters ( $L^{*}, a^{*}$ and $b^{*}$ ) based on the CIELAB system, an three-dimensional color space $^{8}$. According to spectrophotometer data, the whitening improvement occurs mainly by increasing the lightness (higher $L^{*}$ ) and reducing the redness (lower a*) and yellowness (lower b*) b $^{3}$. At 1 week post-bleaching, all treatment groups showed an increase of the $L^{*}$ and a decrease of the $a^{*}$ and b* color parameters. There are clearly limitations in comparing in vitro results with clinical studies once that changes in $\Delta \mathrm{L}^{*}, \Delta \mathrm{a}^{*}$ and $\Delta \mathrm{b}^{*}$ need to be interpreted with caution. Nevertheless, the color parameters data of this in vitro study is in agreement with the results of clinical trials, indicating that lower concentrations of tooth bleaching gels are as effective as higher concentrations $5^{5,17,20,21}$.

The control group showed an increase of the lightness ( $\left.L^{*}\right)$ and also a decrease of the yellowness $\left(b^{*}\right)$ and redness $\left(a^{*}\right)$ during water storage. These changes in the parameters are probably due to the removal of tooth surface pigments, as a consequence of the coffee staining procedure.

The overall color change $\left(\Delta \mathrm{E}^{*}\right)$ values are often used in tooth whitening studies in order to indicate the perceptible tooth color changes after treatment ${ }^{3,11}$. At 1 week post-bleaching, all treatment groups showed $\Delta \mathrm{E}^{*}$ values higher than 13.0. Clinically, such finding could demonstrate that the lower concentration of peroxide-based gels would achieve the same perceptible results as the $37 \%$ carbamide peroxide, frequently used for in-office tooth bleaching. Besides, previous studies have stated that color reversal after bleaching treatment occurs quicker for in-office products than home tray-based bleaching agents ${ }^{16,17,25}$.

Considering that all carbamide peroxide gels evaluated in this study resulted in a similar tooth shade improvement, it could be suggested the use of low carbamide peroxide concentrations for vital tooth bleaching, in accordance with the American Dental Association guidelines, which only assures the safety and efficacy of bleaching treatment using trays with $10 \% \pm 1 \%$ carbamide peroxide application ${ }^{2}$.

The null hypothesis for this study was accepted as the high-concentration carbamide peroxide produced similar tooth color improvement than the bleaching agents containing low carbamide peroxide concentration. Further studies and clinical trials are needed to determine if the same color improvement is obtained with in-office or home-use carbamide peroxide bleaching agents.

\section{CONCLUSIONS}

Within the limitations of this study, it may be concluded that at-home (10 or $16 \%$ carbamide peroxide) or in-office ( $37 \%$ carbamide peroxide) bleaching agents produced a similar color improvement after the end of the treatment.

\section{Clinical relevance}

Tooth bleaching with high or low concentrated carbamide peroxide agents were similarly effective after treatment period. Practitioners must be informed about bleaching techniques in order to provide an evidence-based choice for their patients.

\section{REFERENCES}

1- Alomari Q, El Daraa E. A randomized clinical trial of in-office dental bleaching with or without light activation. J Contemp Dent Pract. 2010;11:E017-24.

2- American Dental Association. Accepted over-the-counter products [online]. [cited $2011 \mathrm{Apr} 1^{\text {st }}$. Available from: http:// www.ada.org/ada/seal/shoppinglist.aspx.

3- American Dental Association. Dentist-dispensed home-use tooth bleaching products [online]. 2006. [cited 2007 May 15 $5^{\text {th }}$. Available from: http://www.ada.org/sections/scienceAndResearch/pdfs/ guide_home_bleach.pdf

4- Association Dentaire Française. Tooth bleaching treatments - a review [online]. 2007. [cited 2010 Feb $9^{\text {th }}$ ]. Available from: http:// www.adf.asso.fr/pdf/DossiersADF_EN/TOOTH-BLEACHING.pdf.

5- Bizhang M, Chun YH, Damerau K, Singh P, Raab WH, Zimmer S. Comparative clinical study of the effectiveness of three different bleaching methods. Oper Dent. 2009;34:635-41.

6- Braun A, Jepsen S, Krause F. Spectrophotometric and visual evaluation of vital tooth bleaching employing different carbamide peroxide concentrations. Dent Mater. 2007;23:165-9.

7- Buchalla W, Attin T. External bleaching therapy with activation by heat, light or laser: a systematic review. Dent Mater. 2007;23:586-96.

8- Commission Internationale De L'Eclairage. Recommendations on uniform colour spaces, colour difference equations and psychometric colour terms. Paris: Bureau Central de la CIE; 1978. 9- Delfino CS, Chinelatti MA, Carrasco-Guerisoli LD, Batista AR, Fröner IC, Palma-Dibb RG. Effectiveness of home bleaching agents in discolored teeth and influence on enamel microhardness. J Appl Oral Sci. 2009;17:284-8.

10- Demarco FF, Meireles SS, Masotti AS. Over-the-counter whitening agents: a concise review. Braz Oral Res. 2009;23:64-70. 11- Joiner A. The bleaching of teeth: a review of the literature. J Dent. 2006;34:412-9.

12- Joiner A. Tooth colour: a review of the literature. J Dent. 2004;32:3-12.

13- Kugel G, Ferreira S, Sharma S, Barker ML, Gerlach RW. Clinical trial assessing light enhancement of in-office tooth whitening. J Esthet Restor Dent. 2009;21:336-47.

14- Kugel G, Papathanasiou A, Williams AJ $3^{\text {rd }}$, Anderson C, Ferreira S. Clinical evaluation of chemical and light-activated tooth whitening systems. Compend Contin Educ Dent. 2006;27:54-62. 15- Marson FC, Sensi LG, Vieira LC, Araújo E. Clinical evaluation of in-office dental bleaching treatments with and without the use of light-activation sources. Oper Dent. 2008;33:15-22.

16- Matis BA, Cochran MA, Eckert G. Review of the effectiveness of various tooth whitening systems. Oper Dent. 2009;34:230-5. 17- Matis BA, Cochran MA, Franco M, Al-Ammar W, Eckert GJ, Stropes $M$. Eight in-office tooth whitening systems evaluated in vivo: a pilot study. Oper Dent. 2007;32:322-7. 
18- Matis BA, Wang Y, Eckert GJ, Cochran MA, Jiang T. Extended bleaching of tetracycline-stained teeth: a 5-year study. Oper Dent. 2006;31:643-51.

19- Meireles SS, Demarco FF, Santos IS, Dumith SC, Della Bona A. Validation and reliability of visual assessment with a shade guide for tooth-color classification. Oper Dent. 2008;33:117-22. 20- Meireles SS, Heckmann SS, Leida FL, Santos Ida S, Della Bona A, Demarco FF. Efficacy and safety of $10 \%$ and $16 \%$ carbamide peroxide tooth-whitening gels: a randomized clinical trial. Oper Dent. 2008;33:606-12.

21- Meireles SS, Santos IS, Della Bona A, Demarco FF. A doubleblind randomized clinical trial of two carbamide peroxide tooth bleaching agents: 2-year follow-up. J Dent. 2010;38:956-63.
22- Ontiveros JC, Paravina RD. Color change of vital teeth exposed to bleaching performed with and without supplementary light. J Dent. 2009;37:840-7.

23- Sulieman M, Addy M, MacDonald E, Rees JS. The effect of hydrogen peroxide concentration on the outcome of tooth whitening: an in vitro study. J Dent. 2004;32:295-9.

24- Sulieman M, Addy M, Rees JS. Development and evaluation of a method in vitro to study the effectiveness of tooth bleaching. J Dent. 2003;31:415-22.

25- Zekonis R, Matis BA, Cochran MA, Al Shetri SE, Eckert G], Carlson TJ. Clinical evaluation of in-office and at-home bleaching treatments. Oper Dent. 2003;28:114-21. 